\title{
Prospective Analysis of Surgical Treatment For Displaced Midshaft Clavicle Fractures in Adults
}

\author{
Gurung $S^{1}, K C D^{2}$
}

\begin{abstract}
Background: The traditional view that the vast majority of midshaft clavicular fractures heal with good functional outcomes following non-operative treatment may be no longer valid for all midshaft clavicular fractures. And it is becoming increasingly apparent that clavicular malunion is a distinct clinical entity with radiographic, orthopedic, neurologic, and cosmetic features.. Recent studies have shown a high prevalence of symptomatic malunion and nonunion after nonoperative treatment of displaced midshaft clavicular fractures. Objective: To analyze the demography of midshaft clavicular fracture and to observe union time, DASH score, and complication of surgical treatment. Materials and Methods: This prospective observational study of 34 cases with midshaft clavicle fracture was conducted in Nepalgunj medical college, Kohalpur in a time span of one year. Patients were treated operatively with plating and followed up at 6 weeks, 12 weeks, 18 weeks, 6 and 12 month. Results: Thirty four patients (Male: 29 Female: 5) with average age 32.95 years (range: 19 to 59 years) were operated for clavicular fracture with male predominance (85.30\%). The mean time for fracture healing was 16.24 weeks and mean DASH score was 13.58. Conclusions: Displaced midshaft clavicular fracture can be effectively managed with plating and have improved functional outcome and shorter time for union.
\end{abstract}

Key words: DASH score, mid shaft clavicle fracture, plate fixation, union

\section{INTRODUCTION}

Clavicle fractures account for around $4 \%$ of all fractures ${ }^{1}$ and up to $44 \%$ of fractures of the shoulder girdle ${ }^{2,3}$. Fractures of the middle third (or mid-shaft) accountfor approximately $80 \%$ of all clavicle fractures ${ }^{2,3}$. Traditionally, non-operativetreatment has been labeled as the "standard" for midshaft fractures regardless of displacement, with the expectation that even severe radiographic malalignmentwould not influence functional results ${ }^{4}$.

Thenon-operative treatment strategy was based on early reports suggesting that clavicular non-unions are very rare. Clavicular mal-union, if present, was reported as being of radiographic interest only, without clinical importance ${ }^{5}$. However, the prevalence of non-union or malunion in displaced midshaft clavicular fractures after conservative treatment is higher than previously presumed. Of all midshaft clavicular fractures, about two-thirds end up having some degree of mal-union ${ }^{6}$. Recent studies reported a nonunion rate up to 15 percent and more ${ }^{7,8}$ and a potential 20 to 25 percent decrease in shoulder functionand arm strength ${ }^{7,8}$. It is becoming increasingly apparent that clavicular malunion is a

1. Dr. Sandeep Gurung

2. Dr. Dipendra K.C.

Address for correspondence:

Dr. Sandeep Gurung

Department of Orthopedics

Nepalgunj Medical College Teaching Hospital,

Kohalpur, Banke, Nepal

Email: sgurung848@gmail.com distinct clinical entity with radiographic, orthopedic, neurologic, and cosmetic features. Increasing reports of complications associated with nonoperative management like symptomatic malunion, nonunion, shortening, droopy shoulder, have stirred towards operative management of clavicle fractures. With recent advancement in technique and implants for fracture fixation, internal fixation is therefore generally considered as the better choice for these fractures and admirable outcomes have been observed.. Internal fixation restores the anatomical continuity of the clavicle, early return to functional activity, the shorter period of immobilization, and less complications $s^{5,9,10}$. Current study evaluates epidemiology and outcome of the clavicular fracture treated with ORIF and plating in NGMCTH Kohalpur.

\section{MATERIALS AND METHODS}

This was a prospective, observational study conducted in NGMCTH Kohalpur in between September 2013 to September 2014. There were 34 patients with displaced midshaft clavicular fracture who had undergone ORIF with plating.Patient's demographic data, mode of injury, Disability of the Arm Shoulder and Hand (DASH) score, union rate, and complication rates were evaluated.

\section{Inclusion criteria}

Patient between eighteen and sixty years with, a completely displaced midshaft fracture of the clavicle (no cortical contact between the main proximal and distal fragments), with no medical contraindications to general anesthesia, and with informed consent. 


\section{Surgical technique}

Surgery was done under general anesthesia with patient in beach chair position. An oblique incision was made centered superiorly over the fracture site. The subcutaneous tissue and platysma muscle were kept together as one layer and extensively mobilized, especially proximally and distally. Care was taken to identify, isolate, and protect any visible, larger branches of the supraclavicular nerves, smaller branches were sacrificed.The fracture site was identified, and the fracture was reduced and fixed with a plate on the superior surface of the bone. The deltotrapezial fascia was closed with interruptednumber-1 absorbable sutures as a distinct layer, followed by skin closure. No drains were used.A sling was used for comfort for seven to ten days, andthen a physiotherapist instructed the patient in active rangeof-motion exercises that were performed at home.

\section{DASH scores}

The Disabilities of Arm, Shoulder and Hand (DASH) Outcome Measure is a validated 30-item, self-report questionnaire designed to describe the disability experienced by people with upper-limb disorders and to monitor changes in symptoms and function over time. The DASH Outcome Measure consists of two components: the disability/symptom section (30 items) and the optional high performance Sport/Music module (4 items). The questions involve the degree of difficulty in performing a variety of physical activities because of problems with the arm, shoulder, or hand. It gives clinicians and researchers the advantage of having a single, reliable instrument that can be used to assess any or all joints in the upper extremity ${ }^{11,12}$. More severely disabled individuals have a higher scale on a scale of 0 to 100.

\section{Follow up}

The patients were seen at $6,12,18$ weeks and at 6 and 12 months, and following factors were assessed:

- Time taken for functional recovery

- $\quad$ Time taken for fracture healing (radiographically judged by obliteration of fracture site by cortical bridging)

- Any specific complaints

- Disability of the Arm, Shoulder and Hand (DASH) score

\section{RESULTS}

Thirty four patients (Male: 29 Female: 5) with average age 32.95 years (range: 19 to 59 years) were operated for clavicular fracture. Among them twenty nine $(85.30 \%)$ were male and five cases were female. Twenty four patients (70.59\%) had clavicle fracture following RTA, followed by fall on outstretched hand on 9 cases $(26.47 \%)$ and physical assault in 1 case $(2.94 \%)$. Twenty patients (58.82\%) were affected on the left side clavicle and 14 cases $(41.18 \%)$ on the right side clavicle.

Associated injuries noted in this study were 2 rib fractures managed conservatively, 1 ipsilateral femur fracture was managed by interlocking intramedullary nail, one case with undisplaced contra lateral tibia fracture managed conservatively and one case of glenoid fracture managed conservatively. The mean time gap between injury and operation was 4.32 days.

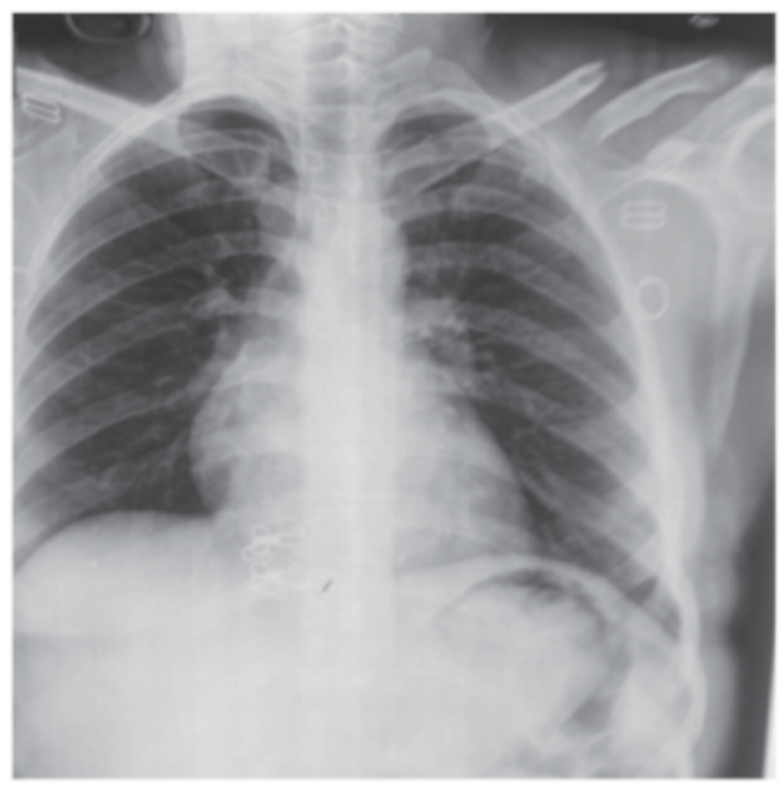

Figure 1 a: Radiograph of $\mathbf{2 2}$ yr old female with clavicle fracture

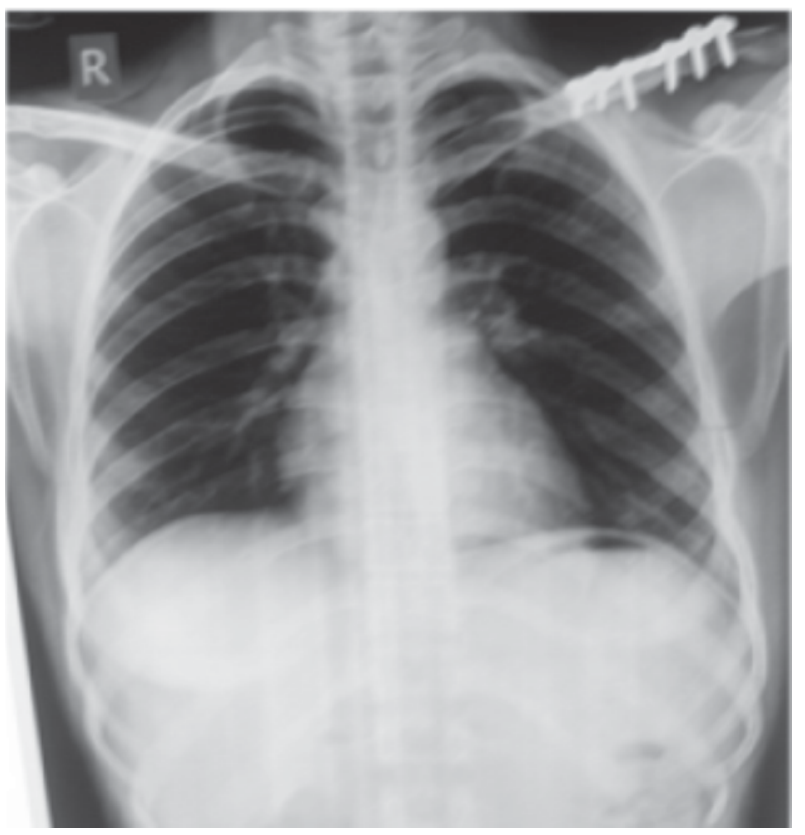

Figure $1 \mathrm{~b}$ : Plate fixation of same patient 


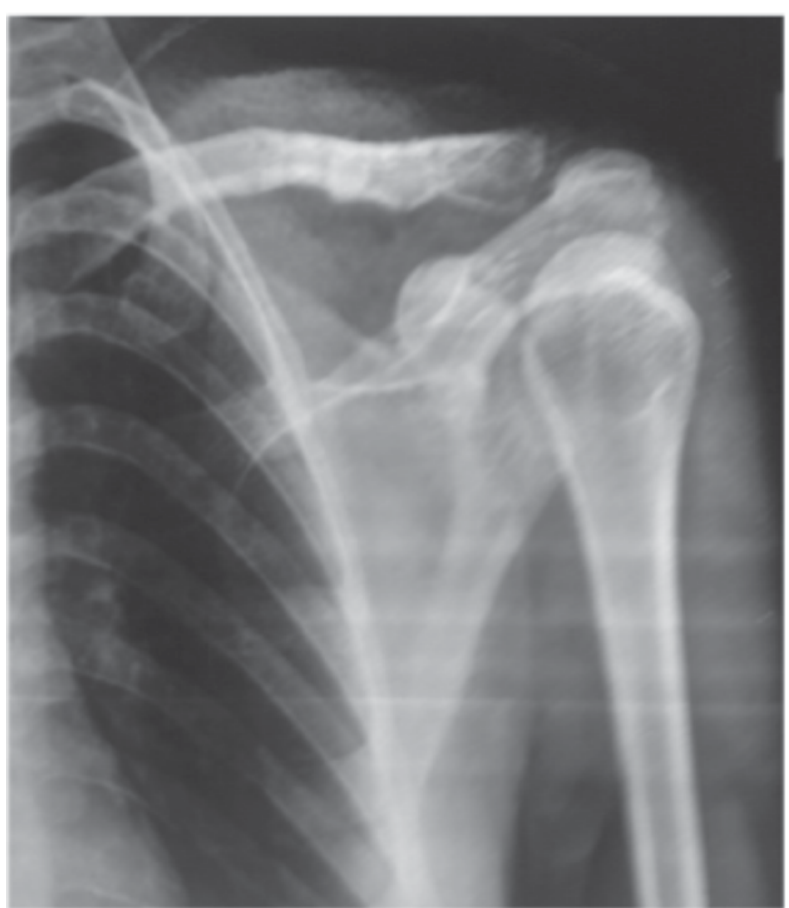

Figure $1 \mathrm{c}$ : Implant removal after 5 month

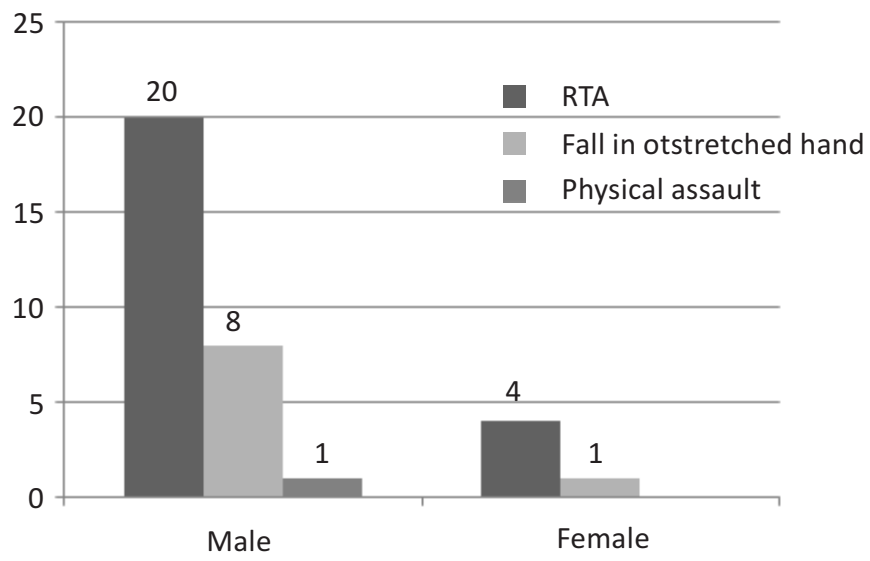

Figure 2: Distribution of patient according to mode of injury among male and female

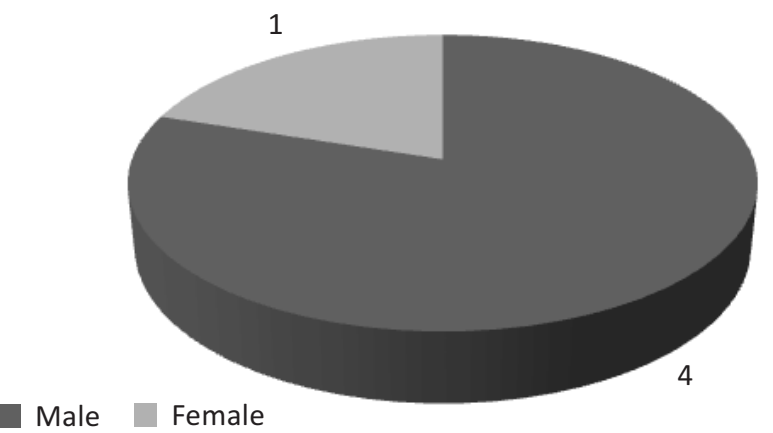

Figure 3: Patient according to associated injuries
Thirty four patients (Male: 29 Female: 5) with average age 32.95 years (range: 19 to 59 years) were operated for clavicular fracture. Among them twenty nine (85.30\%) were male and five cases were female. Twenty four patients $(70.59 \%)$ had clavicle fracture following RTA, followed by fall on outstretched hand on 9 cases (26.47\%) and physical assault in 1 case (2.94\%). Twenty patients (58.82\%) were affected on the left side clavicle and 14 cases $(41.18 \%)$ on the right side clavicle. Associated injuries noted in this study were 2 rib fractures managed conservatively, 1 ipsilateral femur fracture was managed by interlocking intramedullary nail, one case with undisplaced contra lateral tibia fracture managed conservatively and one case of glenoid fracture managed conservatively. The mean time gap between injury and operation was 4.32 days.

\begin{tabular}{|l|c|c|}
\hline & $\begin{array}{c}\text { Mean evidence } \\
\text { of union (weeks) }\end{array}$ & $\begin{array}{c}\text { Mean DASH } \\
\text { score }\end{array}$ \\
\hline Male & 16.13 & 12.94 \\
\hline Female & 16.8 & 17.25 \\
\hline Total & $16.24 \pm 3.74$ & $13.58 \pm 4.38$ \\
\hline
\end{tabular}

\section{TABLE I: Evidence of union and mean DASH score}

The mean time for fracture healing was 16.24 weeks. We did not encounter any major complications. Case no. 23 developed wound infection and was managed with antibiotic and local wound care. Once fracture union had occurred patient underwent hardware removal and irrigation with successful resolution of the infection. Case no 4 developed hardware irritation and was managed conservatively and underwent implant removal after fracture union.

Mean DASH score of the patients in our series was 13.58 . Functionally this was very acceptable. In our series 29 patients had full range of motion of the affected shoulder. Five had difficulty in abduction over 100 degree.

\section{DISCUSSION}

Traditionally, clavicular fractures have been treated nonoperatively. In a study of fifty-two displaced midshaft clavicular fractures, Hillet al. reported that eight patients had a nonunion and sixteen patients had an unsatisfactory outcome on the basis of patient-oriented measures ${ }^{13}$. They concluded that displacement of the fracture fragments by $>2 \mathrm{~cm}$ was associated with an unsatisfactory result. A meta-analysis of recent studies revealed that the rate of nonunion for displaced midshaft clavicular fractures was $2.2 \%$ (ten of 460 patients) after plate fixation compared with $15.1 \%$ (twenty-four of 159 patients) after nonoperative care, a relative risk reduction for nonunion of $86 \%{ }^{14}$. That meta-analysis also showed that primary plate fixation was, contrary to prevailing opinion, a safe and reliable procedure ${ }^{14}$. 
In this study a total of 34 cases with clavicle fracture were operated. The average age of the patients was 32.95 years, among them male predominance was present $(85.30 \%)$ and female were $14.70 \%$. Pearson et al. ${ }^{7}$ have reported the average age of patients sustaining a clavicular fracture is 33 years. Postacchiniet $\mathrm{al}^{15}$ reported that most patients were men (68\%). In this study $70.59 \%$ developed clavicle fracture following RTA. Zlowodzki etal. ${ }^{8}$ and McKee etal. ${ }^{16}$ describeda RTA is the most common trauma mechanism of injury for any clavicular fracture.In our study, $58.82 \%$ had clavicle fractures on the left side. Postacchiniet al. ${ }^{15}$ also described that the left side was involved in $61 \%$ of cases.

The mean time for fracture healing (radiological union) was 16.24 weeks. McKee et al. ${ }^{16}$ described the mean time for fracture healing were 14-16 weeks for operated patients and 24-28 weeks for nonoperated patients. McKee et al. ${ }^{16}$ reported the rate of nonunion in the nonoperated patients $14-24 \%$, and $3.2 \%$ in the operated group The mean DASH score was 13.58 in our study while Vaithilingam $A$ et al. ${ }^{17}$ reported 13.04 as a mean DASH score.

\section{CONCLUSIONS}

In conclusion, primary plate fixation of completely displaced midshaft clavicular fractures results in improved patientoriented outcomes, improved surgeon-oriented outcomes, earlier return to function, and decreased rates of nonunion and malunion. Patients were more satisfied with the shoulder (and its appearance) following operative intervention.

\section{REFERENCE}

1. Lenza M, Belloti JC, Gomes Dos Santos JB, Matsumoto MH, Faloppa F: Surgical interventions for treating acute fractures or non-union of the middle third of the clavicle. Cochrane database of systematic reviews (Online) 2009,4:CD007428.

2. Nowak J, Mallmin H, Larsson S:Theaetiology and epidemiology of clavicular fractures. A prospective study during a two-year period in Uppsala, Sweden. Injury 2000,31(5):353-358.

3. Bravo CJ, Wright CA:Displaced, comminuted diaphyseal clavicle fracture. The Journal of hand surgery2009,34(10):1883-1885.

4. CS N. Fractures of the clavicle. In: Rockwood Jr CA, Green DP, editors. Fractures in adults. 2nd ed. Philadelphia: JB Lippincott; 1984. p. 707-13.

5. Canadian Orthopaedic Trauma Society:Nonoperative treatment compared with plate fixation of displaced midshaft clavicular fractures. A multicenter, randomized clinical trial.J Bone Joint Surg Am2007,89:1-10.

6. Hillen RJ, Burger BJ, Poll RG, de GA, Robinson CM:Malunion after midshaft clavicle fractures in adults. Acta Orthop2010,81:273279.

7. Pearson AM, Tosteson ANA, Koval KJ, McKee MD, Cantu RV, Bell JE, Vicente M:Is Surgery for Displaced, Midshaft Clavicle Fractures in Adults Cost-Effective? Results Based on a Multicenter Randomized, Controlled Trial. Journal of Orthopaedic Trauma 2010,24:426-433.

8. Zlowodzki M, Zelle BA, Cole PA, Jeray K, McKee MD:Treatment of acute midshaft clavicle fractures: systematic review of 2144 fractures: on behalf of the Evidence-Based Orthopaedic Trauma Working Group. J Orthop Trauma 2005,19:504-507.

9. Böhme J, Bonk A, Bacher GO, Wilharm A, Hoffmann R, Josten C. Current treatment concepts for mid-shaft fractures of the clavicle-results of a prospective multicentre study. Z OrthopUnfall2011;149:68-76.

10. Gille J, Schulz A, Wallstabe S, Unger A, Voigt C, Faschingbauer M. Hook plate for medial clavicle fracture. Indian J Orthop 2010;44:221-3.

11. Beaton DE, Katz JN, Fossel AH, Wright JG, Tarasuk V, Bombardier C: Measuring the whole or the parts? Validity, reliability, and responsiveness of the Disabilities of the Arm, Shoulder and Hand outcome measure in different regions of the upper extremity.J Hand Ther2001,14:128-146.

12. Hudak PL, Amadio PC, Bombardier C:Development of an upper extremity outcome measure: the DASH (disabilities of the arm, shoulder and hand) [corrected]. The Upper Extremity Collaborative Group (UECG).Am J Ind Med1996,29:602-608.

13. Hill JM, McGuire MH, Crosby LA. Closed treatment of displaced middle-third fractures of the clavicle gives poor results. J Bone Joint Surg Br. 1997;79:537-9.

14. Robinson CM. Fractures of the clavicle in the adult. Epidemiology and classification. J Bone Joint SurgBr. 1998;80:476-84.

15. Postacchini F, Gumina S, De Santis P, Albo F. Epidemiology of clavicle fractures. J 41Shoulder Elbow Surg 2002;11:452-6.

16. McKee MD, Pedersen EM, Jones C, Stephen DJ, Kreder HJ, Schemitsch $\mathrm{EH}$, et al.Deficits following nonoperative treatment of displaced midshaft clavicular fractures. J Bone Joint Surg Am 2006;88:35-40.

17. Vaithilingam A, Ghosh S, Chaudhuri A, Datta S, Gupta G, Dugar N, Dutta S. Fracture clavicle: Operative versus conservative management. Saudi J Sports Med 2015;15:31-6. 